Bangladesh J. Bot. 40(2): 133-138, 2011 (December)

\title{
PHYSIOLOGY OF SEED YIELD IN MUNGBEAN: GROWTH AND DRY MATTER PRODUCTION
}

\author{
MMA MONDAL ${ }^{*}$, MSA FAKIR ${ }^{1}$, M NuRUL ISLAM ${ }^{2}$ AND MA SAMAD ${ }^{3}$ \\ Crop Physiology Division, Bangladesh Institute of Nuclear Agriculture, \\ Mymensingh, Bangladesh
}

Key words: Seed yield, Mungbean, Growth, Dry matter

\begin{abstract}
Growth rate of mungbean was very slow during the vegetative phase in all the four genotypes. A relatively smaller portion of total dry matter (TDM) was produced before flower initiation and the bulk of it after anthesis. The maximum crop growth rate (CGR) was observed due to maximum leaf area (LA) development during the pod filling stage in all the genotypes. LA and CGR contributed to the superior TDM production. It appeared that a high yielding mungbean genotype should possess larger LA, high TDM production ability, superior CGR at all the growth stages, high relative growth rate and net assimilation rate at the vegetative stage as superior yield components.
\end{abstract}

\section{Introduction}

In spite of the best efforts for improving the mungbean varieties, the yield remains low. Several reports have been made about the contribution of various yield components towards yield (Power and Bhatia 1980, Ahmed et al. 1993, Hakim 2008). The yield components depend on some physiological traits. To understand the physiological basis of yield difference among the genotypes of mungbean, it is essential to quantify the components of growth, and the variation, if any, may be utilized in crop improvement. Variation in dry matter accumulation and pod production in different genotypes may be related to some factors such as leaf area (LA), crop growth rate (CGR), net assimilation rate (NAR) and relative growth rate (RGR). Pandey et al. (1978) analyzed growth parameters of five varieties of blackgram in order to study the physiological causes of yield differences and observed differences in CGR, NAR, RGR and LA among the varieties. Egli and Zhen-wen (1991) suggested that seeds per unit area were related to canopy photosynthesis during flowering and pod set and canopy photosynthesis rate is determined through LAI and CGR. A plant with optimum LAI and NAR may produce higher biological yield as well as seed yield (Dutta and Mondal 1998). The dry matter accumulation may be the highest if LAI attains its maximum value within the shortest possible time (Pawar and Bhatia 1980, Sarwar et al. 2004, Khan and Khalil 2010). Not only TDM production, the capacity of efficient partitioning between the vegetative and reproductive parts may produce high economic yield (Thakare et al. 1981, Mondal 2007). A better understanding of crop growth and yield parameters and the partitioning of assimilates into seed formation would help to expedite yield improvement of field crops. Very little work has been reported on this regard in mungbean. A detailed analysis of growth and yield parameters of high and low yielding mungbean genotypes was therefore undertaken.

\section{Materials and Methods}

Experiments were performed at the Field Laboratory, Bangladesh Agricultural University (BAU), Mymensingh ( $\left.24^{\circ} 8^{\prime} \mathrm{N} 90^{\circ} 0^{\prime} \mathrm{E}\right)$, Bangladesh in Kharif-I (February-May) season of 2008 and 2009. Four mungbean (Vigna radiata (L.) Wilczek) genotypes of which two high (MB-35 and MB-45) and two low (MB-16 and MB-43) yielding were used as planting material. The soil of

*Corresponding author. ${ }^{1}$ Crop Botany Department, Bangladesh Agricultural University, Mymensingh, Bangladesh. ${ }^{2}$ Department of Botany, University of Dhaka, Dhaka-1000, Bangladesh. ${ }^{3}$ Plant Breeding Division, Bangladesh Institute of Nuclear Agriculture, Mymensibgh, Bangladesh. 
the experimental area of BAU was silty loam having a total nitrogen $0.06 \%$, organic matter $1.15 \%$, available phosphorus $18.5 \mathrm{ppm}$, exchangeable potassium $0.28 \mathrm{meq} / 100 \mathrm{~g}$, sulphur $18 \mathrm{ppm}$ and $\mathrm{pH}$ 6.8. Seeds were sown on 14 and 12 March for the year of 2008 and 2009, respectively. A RCB design with three replications was followed in both the years. A unit plot size of $4 \mathrm{~m} \times 3 \mathrm{~m}$ with plant spacing of $30 \mathrm{~cm} \times 10 \mathrm{~cm}$ was used. Seeds were sown in line and two weeks after germination, the plants were thinned to a density of 30 plants $/ \mathrm{m}^{2}$. Cultural practices were the same in both the seasons. Urea, triple superphosphate, muriate of potash and gypsum were used as a source of nitrogen, phosphorus, potassium and sulphur at the rate of $40,120,80$ and $30 \mathrm{~kg} / \mathrm{ha}$, respectively at the time of final land preparation. First weeding was done followed by thinning at about 21 days after sowing (DAS). One irrigation was given at 25 DAS at both the locations. Insecticide (Ripcord 50 EC @ 0.025\%) was sprayed at the flowering and the fruiting stage (55 DAS) to control shoot and fruit borer.

To study ontogenetic growth characteristics, a total of seven harvests were made in 2008 and six harvests in 2009 because, plants matured seven days earlier in 2009 than in 2008. The second and third rows of each plot were used for sampling. The first crop sampling was done at 25 DAS and continued at an interval of eight days up to 72 DAS in 2008 and 65 DAS in 2009 i.e. till attaining physiological maturity. From each sampling, a unit area of $0.3 \mathrm{~m}^{2}$ in two adjacent rows of $0.5 \mathrm{~m}$ (10 plants) were randomly selected from each plot and uprooted for collecting necessary parameters. The plants were separated into roots, stems, leaves and pods, and the corresponding dry weights were recorded after oven drying at $80 \pm 2^{\circ} \mathrm{C}$ for 72 hours. The leaf area of each sample was measured by automatic leaf area meter (Model: LICOR 3000, USA). The growth analysis was carried out following the formulae of Hunt (1978). The yield contributing characters were recorded at harvest from ten competitive plants of each plot. The seed yield was recorded from five rows of each plot $(1.50 \mathrm{~m} \times 3.0 \mathrm{~m})$ and converted into seed weight/plant by dividing the plant number. The collected data were analyzed statistically by using computer package programme, MSTAT-C.

\section{Results and Discussion}

The differences among the genotypes for total dry mass (TDM) and leaf area (LA) were perceptible only after 41 DAS in 2008 whereas in 2009, at all growth stages (Figs 1 and 2). The differential genotypic performance for LA and their relation to the DM production, at each growth stage could be associated to the genetic make up of the genotypes. A common feature of mungbean genotypes was slow accumulation of TDM and LA development upto 41 DAS followed by a rapid increase after commencement of flowering. Flowering started at 40-45 DAS, depending on genotypes. The faster TDM accumulation after the starting of reproductive stage was the result of increase of LA (Khan and Khalil 2010). TDM production in all the genotypes increased with age till physiological maturity whereas LA followed a typical sigmoid pattern with respect to time. In $2008 \mathrm{LA}$ of three genotypes increased up to the physiological maturity and in the remaining genotype (MB-16) LA increased up to 65 DAS followed by a decline. In 2009, LA increased with age till 57 DAS in all the four genotypes followed by a decline because of abscission of older leaves. Results indicated that high yielding genotypes (MB-35 and MB-45) always showed superiority in TDM and LA production compared to low yielding ones (MB-16 and MB-43) at most of the growth stages. These results indicate that LA and TDM are the most important parameters for increasing grain yield in mungbean. This result is consistent to Ahmed et al. (2003) who observed seed yield depends on LA and TDM production in mungbean. 

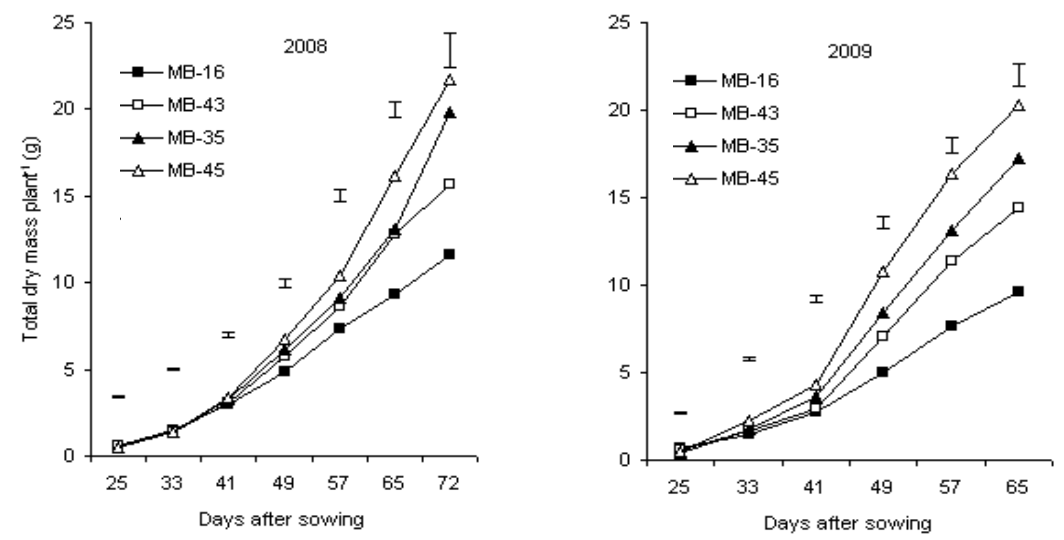

Fig. 1. Changes in total dry mass at different stages of growth in four mungbean genotypes. Vertical bars represent LSD (0.05).
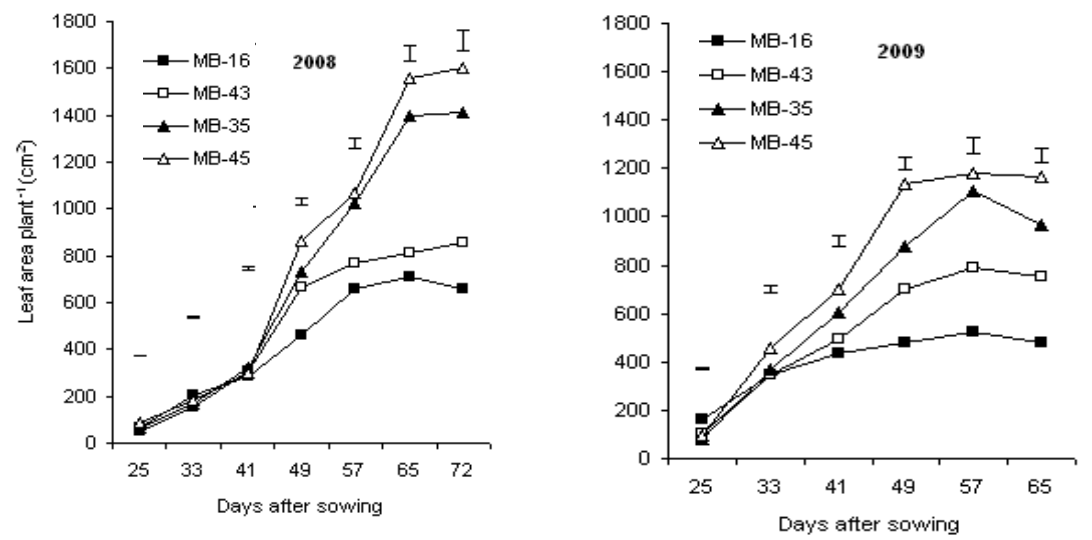

Fig. 2. Leaf area development at different stages of growth in four mungbean genotypes. Vertical bars represent LSD (0.05).

Crop growth rate (CGR) tended to increase with the advancement of growth stage till 57-65 DAS in 2008 and 49-57 DAS in 2009 (Fig. 3). Genotypes differed significantly in CGR at all the growth stages except at 25-33 DAS in 2008. It is evident that mungbean had three distinct growth phases: early slow growth (up to 41 DAS, before flower initiation), followed by a rapid growth (41-60 DAS, flowering and pod filling stages) and then decline growth phase at pod maturity stage. The slow growth rate at early growth stage was associated with lower LA and TDM production. The initial slow growth favours weed growth and development; thus crop ultimately suffers a loss. The selection of genotypes with rapid growth rate in the early part of a crop life is therefore warranted. In the present experiment, high yielding genotypes had greater CGR than the low yielding ones that is the desirable characters. At the later stage of pod growth and development (57-72 DAS), there was a decline in CGR, possibly owing to similar decline in LA during this stage (Fig. 2).

Relative growth rate (RGR) declined with age in 2008 whereas in 2009, RGR decreased rapidly from 25-33 DAS to 33-41 DAS, then moderately increased till 41-49 DAS followed by a decline except in MB-16 (Fig. 4). RGR of MB-16 declined with age. In both the seasons, RGR 
was higher in high yielding genotypes than the low yielding ones at most of the growth stages. Kollar et al. (1970) observed a decrease in RGR as the season advanced.
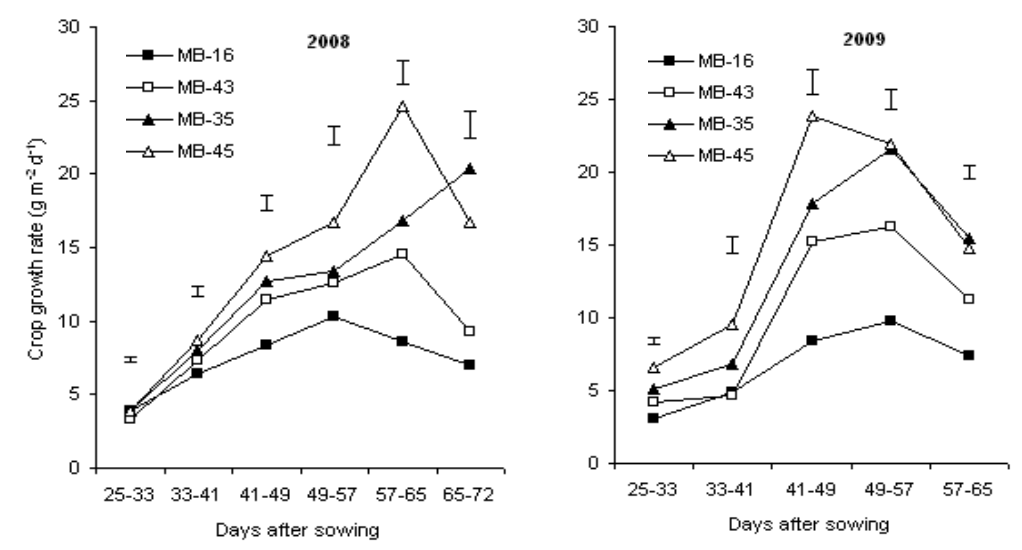

Fig. 3. Pattern of crop growth rate in four mungbean genotypes during their growth period. Vertical bars represent LSD (0.05).
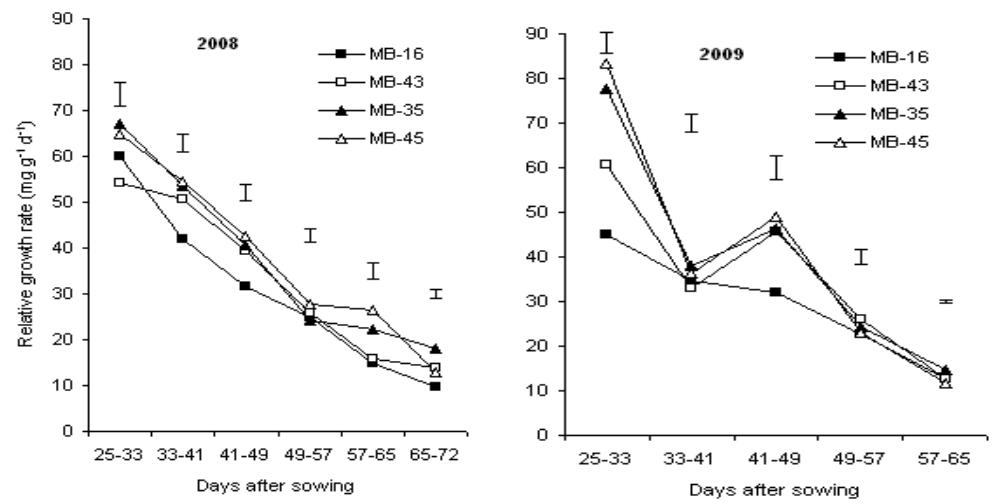

Fig. 4. Pattern of relative growth rate in four mungbean genotypes during their growth period. Vertical bars represent LSD (0.05).

The pattern of net assimilation rate (NAR) in both the seasons was not similar (Fig. 5). The changes in NAR varied widely in two seasons at different times and were brought about through plastic changes in leaves which in turn were induced by the light environment of the growth season. NAR rapidly declined with age in 2008 except in MB-45. NAR of MB-45 increased rapidly from 25-33 DAS to 33-41 DAS followed by a rapid decline up to 57-65 DAS. In 2009, NAR did not follow any definite pattern among the genotypes. Out of four genotypes three showed decline in NAR from 25-33 DAS to 33-41 DAS followed by an increase till 41-49 DAS and then again declined up to the maturity. The genotype MB-16 showed increasing trend with age. The sharp rise in NAR during the reproductive stage (in 2009 only) was probably due to increased demand of assimilates by the growing seed (Hamid et al. 1991). However, maximum NAR in both the seasons was between 25 and 33 DAS, at the vegetative stage. NAR declined at later growth stages (reproductive stage) of 2008 may be attributed to excessive mutual shading as the LA was maximum during this period and increased number of old leaves could have lowered the photosynthetic efficiency (Salam et al. 1987). In grain legume, the excess LA was reported to 
have lowered NAR drastically and resulted in a decreased dry matter accumulation, which probably resulted from excessive mutual shading (Pandey et al. 1978). Further, at the early growth stages, NAR was higher in the high yielding genotypes than the low yielding ones.
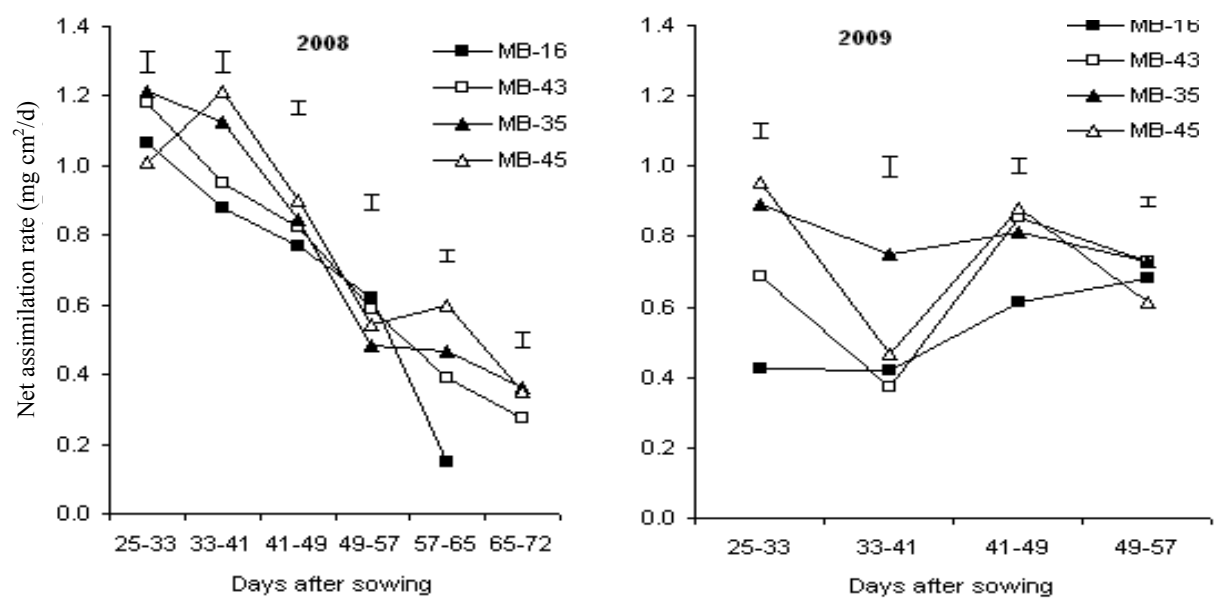

Fig. 5. Net assimilation rate of four mungbean genotypes at different stages of growth. Vertical bars represent LSD (0.05). In 2009, the NAR was negative value at 57-65 DAS.

Table 1. Yield contributing characters and yield in four mungbean genotypes.

\begin{tabular}{|c|c|c|c|c|c|c|c|}
\hline \multicolumn{2}{|c|}{ Treatment } & $\begin{array}{l}\text { Pods/plant } \\
\text { (no.) }\end{array}$ & $\begin{array}{l}\text { Seeds/pod } \\
\text { (no.) }\end{array}$ & $\begin{array}{c}\text { Single pod } \\
\text { weight }(\mathrm{mg})\end{array}$ & $\begin{array}{c}100 \text {-seed } \\
\text { weight }(\mathrm{g})\end{array}$ & $\begin{array}{c}\text { Seed yield/ } \\
\text { plant }(\mathrm{g})\end{array}$ & $\begin{array}{c}\text { Harvest } \\
\text { index (\%) }\end{array}$ \\
\hline \multicolumn{8}{|l|}{ Year } \\
\hline \multicolumn{2}{|c|}{2008} & 26.5 & 10.3 & $482 \mathrm{~b}$ & $3.97 \mathrm{~b}$ & $6.83 \mathrm{~b}$ & 34.8 \\
\hline \multicolumn{2}{|c|}{2009} & 28.3 & 11.1 & $722 \mathrm{a}$ & $4.81 \mathrm{a}$ & $7.73 \mathrm{a}$ & 36.5 \\
\hline \multicolumn{2}{|c|}{ F-test } & NS & $* *$ & $* *$ & $* *$ & $* *$ & NS \\
\hline \multicolumn{8}{|c|}{ Genotype } \\
\hline \multicolumn{2}{|c|}{ MB-16 } & $11.1 \mathrm{~d}$ & $9.95 \mathrm{c}$ & $695 a$ & $5.24 \mathrm{a}$ & $3.65 \mathrm{c}$ & $42.2 \mathrm{a}$ \\
\hline \multicolumn{2}{|c|}{ MB-43 } & $17.5 \mathrm{c}$ & $10.6 \mathrm{~b}$ & $650 \mathrm{~b}$ & $4.85 \mathrm{~b}$ & $5.40 \mathrm{~b}$ & $35.3 \mathrm{~b}$ \\
\hline \multicolumn{2}{|c|}{ MB-35 } & $42.6 \mathrm{a}$ & $11.1 \mathrm{ab}$ & $503 \mathrm{~d}$ & $3.58 \mathrm{~d}$ & $9.88 \mathrm{a}$ & $33.9 \mathrm{~b}$ \\
\hline \multicolumn{2}{|c|}{ MB-45 } & $38.4 \mathrm{~b}$ & $11.2 \mathrm{a}$ & $561 \mathrm{c}$ & $3.87 \mathrm{c}$ & $10.2 \mathrm{a}$ & $31.2 \mathrm{~b}$ \\
\hline \multicolumn{2}{|c|}{ F-test } & $* *$ & $* *$ & $* *$ & $* *$ & $* *$ & $* *$ \\
\hline \multicolumn{8}{|c|}{ Interaction of season and genotype } \\
\hline \multirow[t]{4}{*}{2008} & MB-16 & $10.3 \mathrm{~d}$ & $9.30 \mathrm{f}$ & $549 \mathrm{e}$ & $5.04 \mathrm{~b}$ & $3.53 \mathrm{~d}$ & $38.9 \mathrm{~b}$ \\
\hline & MB-43 & $22.8 \mathrm{c}$ & $10.0 \mathrm{ef}$ & $530 \mathrm{e}$ & $4.48 \mathrm{c}$ & $6.21 \mathrm{c}$ & $33.0 \mathrm{~d}$ \\
\hline & MB-35 & $43.3 \mathrm{a}$ & $10.4 \mathrm{de}$ & $403 \mathrm{~g}$ & $3.05 \mathrm{e}$ & $8.84 \mathrm{~b}$ & $35.5 \mathrm{bcd}$ \\
\hline & MB-45 & $40.1 \mathrm{ab}$ & $11.4 \mathrm{ab}$ & $447 \mathrm{f}$ & $3.32 \mathrm{e}$ & $8.76 \mathrm{~b}$ & $31.6 \mathrm{~d}$ \\
\hline \multirow[t]{4}{*}{2009} & MB-16 & $11.8 \mathrm{~d}$ & $10.6 \mathrm{cde}$ & $841 \mathrm{a}$ & $5.45 \mathrm{a}$ & $3.78 \mathrm{~d}$ & $45.4 \mathrm{a}$ \\
\hline & MB-43 & $12.3 \mathrm{~d}$ & $11.2 \mathrm{abc}$ & $770 \mathrm{~b}$ & $5.23 \mathrm{ab}$ & $4.60 \mathrm{~d}$ & $37.6 \mathrm{bc}$ \\
\hline & MB-35 & $41.9 \mathrm{a}$ & $11.8 \mathrm{a}$ & $603 \mathrm{~d}$ & $4.11 \mathrm{~d}$ & $10.9 \mathrm{a}$ & $32.3 \mathrm{~cd}$ \\
\hline & MB-45 & $36.8 \mathrm{~b}$ & $11.0 \mathrm{bcd}$ & $675 \mathrm{c}$ & $4.43 \mathrm{c}$ & $11.6 \mathrm{a}$ & $30.9 \mathrm{~d}$ \\
\hline \multicolumn{2}{|c|}{ F-test } & $* *$ & $* *$ & $* *$ & $* *$ & $* *$ & $* *$ \\
\hline \multicolumn{2}{|c|}{$\mathrm{CV}(\%)$} & 9.30 & 3.93 & 3.20 & 3.50 & 8.50 & 8.41 \\
\hline
\end{tabular}

In a column, figures bearing same letter(s) do not differ significantly at $\mathrm{p} \leq 0.05$ by DMRT; NS $=$ Not significant; ** indicate significant at $1 \%$ level of probability. 
Results showed that, MB-35 and MB-45 genotypes performed higher grain yield than, MB-16 and MB-43 genotypes due to the production of higher number of pods/plant and seeds/pod (Table 1). Although the low yielding genotypes, MB-16 and MB-43 produced larger pod and bolder seed with superior harvest index than the high yielding genotypes MB-35 and MB-45, yet they showed lower yield due to a fewer pod production. Mondal (2007) observed that seed yield of mungbean had no positive relation with pod and seed size as well as harvest index. In the present experiment, similar result was also observed. Results further revealed that those genotypes which had higher LA, TDM, CGR, RGR and NAR also showed higher seed yield in mungbean. The interaction effect of season and genotype on yield attributes and yield was significant (Table 1) indicating season had a great influence on growth and yield in mungbean.

It appeared that in addition to superior characters for yield components, a high yielding mungbean genotype should posses a relatively larger leaf area with superior growth parameters.

\section{References}

Ahmed F, O Hirota, Y Yamada and MA Rahman 2003. Growth characteristics and yield of mungbean varieties cultivated under different shading conditions. Japn. J. Trop. Agric. 47: 1-8.

Ahmed JU, EL Rosario, MA Malek 1993. Correlation of reproductive abscission, seed yield and yield components in mungbean. Bangladesh J. Plant Breed. Genet. 6: 25-29.

Dutta RK and MMA Mondal 1998. Evaluation of lentil genotypes in relation to growth characteristics, assimilate distribution and yield potential. LENS Newsl. 25: 51-55.

Egli DB and Y Zhen-wen 1991. Crop growth rate and seeds per unit area in soybean. Crop Sci. 31: 439-442.

Hakim L 2008. Variability and correlation of agronomic characters of mungbean germplasm and their utilization for variety improvement programme. Indonesian J. Agric. Sci. 9: 24-28.

Hamid A, W Agata, AFM Maniruzzaman and AM Ahad 1991. Physiological aspects of yield improvement in mungbean. In: Advances in pulses research in Bangladesh. pp. 95-102. Proc. Second National Workshop on Pulses. June 6-8, 1989, BARI, Gazipur.

Hunt R 1978. Plant growth analysis studies in biology. Edward Arnold, London.

Khan A and A Khalil 2010. Effect of leaf area on dry matter production in aerated mungbean seed. Int. J. Plant Physiol. Biochem. 2: 52-61.

Koller HR, WE Nyquist and IS Chorash 1970. Growth analysis of soybean community. Crop Sci. 10: 407-412.

Mondal MMA 2007. A study of source-sink relationship in mungbean. Ph. D Thesis, Dept. Crop Bot., Bangladesh Agric. Univ., Mymensingh.

Pandey RK, MC Saxena and VB Singh 1978. Growth analysis of blackgram genotypes. Indian J. Agric. Sci. 48: 466-473.

Pawer SE and CR Bhatia 1980. The basis for grain yield differences in mungbean cultivars and identification of yield limiting factors. Theor. Appl. Genet. 57: 171-175.

Salam MA, AFM Moniruzzaman and SI Chowdhury 1987. Growth analysis in mungbean. Bangladesh J. Nuclear Agric. 3: 58-64.

Sarwar S, MS Sadiq, M Saleem, G Abbas 2004. Selection criteria in $\mathrm{F}_{3}$ and $\mathrm{F}_{4}$ populations of mungbean. Pak. J. Bot. 36: 297-310.

Thakare, RG, SE Pawar, DC Jashua, R Mitra and CR Bhatia 1981. Variation in some physiological components of yield in induced mutants of mungbean. In: Induced mutations- a tool in plant breeding. pp. 213-226. IAEA-SM-251/5. International Atomic Energy Agency, Vienna. 